\title{
REVISÃO NARRATIVA: RADIOSSENSIBILIDADE, RADIOTERAPIA E POTENCIAIS BIOMARCADORES
}

\author{
Ewerton Clementino Diniz ${ }^{1}$
}

RESUMO: A exposição à radiação ionizante pode levar a um estado inflamatório exacerbado, essa resposta está associada a radiossensibilidade individual, sendo assim fator limitante de terapias a base de radiação. Ainda não existem testes clínicos específicos para aferir a radiossensibilidade individual, contudo, algumas moléculas apresentam-se como potenciais biomarcadores. Esse estudo de revisão objetivou avaliar a literatura acerca da radiossensibilidade e potenciais marcadores da sensibilidade a radiação para análise de literatura palavras chaves foram inseridas em bancos de dados (GOOGLE SCHOLAR, LILACS, SCIELO e PUBMED) e artigos e teses que abordavam os temas foram selecionadas. A literatura apresenta estudos que indicam que essas moléculas podem vir a ser potenciais biomarcadores da radiossensibilidade individual, contudo, mais estudos precisam ser feitos.

Palavras-chaves: Radiossensibilidade. Biodosimetria. Dosimetria Citogenética. Biomarcadores da Radiação.

ABSTRACT: Exposure to ionizing radiation can lead to an exacerbated inflammatory state, this response is associated with individual radiosensitivity, thus being a limiting factor for radiation-based therapies. There are still no specific clinical tests to assess individual radiosensitivity, however, some molecules present themselves as potential biomarkers. This review study aimed to evaluate the literature on radiosensitivity and potential markers of radiation sensitivity for literature analysis keywords were entered into databases (GOOGLE SCHOLAR, LILACS, SCIELO and PUBMED) and articles and theses that addressed the themes were selected. The literature presents studies that indicate that these molecules may be potential biomarkers of individual radiosensitivity, however, more studies need to be done.

Keywords: Radiosensitivity. Biodosimetry. Cytogenetic Dosimetry e Radiation Biomarker.

\footnotetext{
${ }^{\mathrm{I}}$ Mestre pelo Programa de Pós-Graduação em Engenharia Biomédica (PPGEB - UFPE), com atividades de pesquisa na área de Bioengenharia. Bacharel em Biomedicina pela Universidade Federal de Pernambuco (UFPE).E-mail: ewertonclementinodiniz@hotmail.com
} 


\section{INTRODUÇÃO}

A terapia com radiações ionizantes (radioterapia) é um dos mais eficazes tratamentos (isoladamente ou em associação) utilizados contra diversos tipos de tumores. Sua utilização remota a Ioo anos e é empregada em mais de metade dos tumores malignos (HENDRY et al., 2006; SOUZA-SILVA et al., 2014).

Embora seja uma terapia com resultados positivos, não é livre de efeitos adversos que em sua grande maioria resultam da interação da radiação ionizante com a molécula de DNA. Os danos ao DNA são ocasionados por dois mecanismos distintos chamados de efeitos direto e indireto, quando o dano é oriundo da interação direta da RI com a molécula do DNA ocorre o efeito direto, já o indireto se dá quando o dano na molécula do DNA é originado pelo contato com moléculas tóxicas oriundas da interação da radiação ionizante com a molécula da água (radiólise da água) (AZZAM, 2012; HENDRY et al., 2016).

Segundo consta na literatura cientifica as reações adversas apresentadas nos sistemas humanos após radioexposição é oriunda da radiossensibilidade individual. Sendo assim a radiossensibilidade pode ser descrita como uma característica intrínseca e associada ao surgimento dos efeitos adversos exacerbados que surgem no corpo humano após radioexposição (BURNET et al., 1992; 1996).

O processo inflamatório subsequente a degradação do DNA é mediada por diversos sinais pro e anti-inflamatórios, as proteínas responsáveis por essa modulação são as citocinas que são expressas por diferentes células durante todo o processo inflamatório (FRANÇOIS et al, 2013).

Não há um indicador clínico ou laboratorial para definição de protocolos de tratamentos envolvendo a radiossensibilidade individual. Nesse sentido, pesquisas envolvendo metabólitos celulares vêm ganhando espaço como potenciais biomarcadores de radiossensibilidade (Barnett et al., 2013), como é o caso das moléculas utilizadas nos métodos biodosimétricos clássicos como o uso de aberrações cromossômicas utilizadas nas técnicas citogenéticas apresentam também potencial como biomarcador $\mathrm{da}$ radiossensibilidade também existem outros potenciais biomarcadores como a proteína $\mathrm{P}_{53}$, os resíduos da $\mathrm{H}_{2} \mathrm{~A}$ e as citocinas. 


\section{METODOLOGIA}

$\mathrm{O}$ artigo categoriza-se como pesquisa bibliográfica, no qual o objetivo principal foi discutir a seguinte questão norteadora: "RADIOSENSIBILIDADE E POTENCIAIS BIOMARCADORES"; para este fim foram realizadas buscas em bases de dados, a saber, literatura Latino Americana e do Caribe em Ciências da Saúde (LILACS), scientific electronic library online (SCIELO) e PUBMED. As palavras chaves utilizadas nas buscas foram "RADIOSENSITIVITY”, "BIODOSIMETRY”, "CYTOGENETIC DOSIMETRY" e "RADIATION BIOMARKER".

Como critérios de inclusão foram selecionados apenas trabalhos que faziam parte do escopo do tema proposto pela questão norteadora em qualquer ano de publicação. Com os critérios de inclusão estabelecidos foi realizada uma primeira leitura aos resumos dos trabalhos como etapa de triagem para escolha dos artigos que comporiam a amostra do trabalho e após leitura dos resumos, aplicação dos critérios e exclusão dos divergentes e duplicatas a amostragem final foi composta por 29 artigos selecionados pelo autor.

\section{DISCUSSÃO}

No século XIX Wilhelm Röntgen descobriu e publicou sobre o raio-X onde observou o poder dos novos raios de penetrarem em materiais sólido e tecidos humanos, motivados pela recente descoberta vários pesquisadores como o Henri Becquerel, Marie e Pierre Curie descobriram o que denominaram de "radioelementos", como o urânio e o tório, que emitiam um tipo de radiação e o chamaram de "radioelementos". Becquerel notou a emissão da radioatividade em filmes em contato com urânio descobrindo então a radioatividade natural (BECQUEREL, I896; HOLST, 1995).

A aplicação terapêutica foi chamada de tele-Röntgen-gama-terapia percussora $\mathrm{da}$ teleterapia moderna, já a utilização de fontes radioativas junto ao inseridas corpo humano chamou-se Curie-terapia precursora da atual braquiterapia (WESTE E BARNETT, 20II).

Nas primeiras décadas não existiam protocolos adequados, padronização dos equipamentos e não havia um conceito comum de dose ideal de radiação, sendo assim não havia fundamentação clara sobre aplicação e o resultado da interação das radiações com os sistemas humanos, somou-se a isso os relatos dos efeitos adversos, tais como queimaduras, 
dermatites e outras sequelas o que levantavam dúvidas à utilização generalizada dos raios ionizantes (HOLST, 1995).

Ao longo do século XX houve a convergência de diversas disciplinas como: a medicina, a física, a computação e a robótica, resultando na radioterapia moderna que atualmente é uma das modalidades terapêuticas mais empregadas e eficazes no combate ao câncer (IAEA,2010).

As reações adversas exacerbadas constituem-se fatores limitantes dos tratamentos com radioterapia, estima-se que $80 \%$ das variações nas reações dos tecidos sadios ao serem expostos aos raios ionizantes não podem ser explicadas pela influência de fatores físicos, portanto, tudo indica que essas variações são influência direta de fatores genéticos intrínsecos e que determinam a resposta celular ao dano produzido pelas radiações ionizantes (TURESSON et al., 1996; WRIGHT, 2006).

Bergonié e Tribondeau foram em 1906 os pioneiros ao realizarem estudos com a radiossensibilidade, os dois observaram que a radiossensibilidade variava em funções do tecido biológico afetado e o deu estado metabólico. O trabalho de Bergonié e Tribondeau foram a base para formular o que hoje conhecemos como lei da radiossensibilidade onde: quanto menor for a diferenciação celular maior é sua radiossensibilidade; órgãos e tecidos mais jovens são mais radiosensíveis; quanto maior a atividade metabólica, maior a radiossensibilidade; quanto maiores as taxas de proliferação e crescimento tecidual maior será a radiossensibilidade (BERGONIÉ, 1959).

\section{I Biomarcadores dosimétricos}

Devido aos danos causados pela exposição, seja laboral, terapêutica ou acidental as radiações ionizantes, métodos físicos de dosimetria são insuficientes em casos de suspeita de exposição acidental seja continua ou não, sendo assim, sempre se buscaram mecanismos para monitorar e estimar as doses recebidas (CASTRO-VOLIO 2013).

Segundo Castro-Volio 2013 existem alguns pré-requisitos para avaliar a utilidade de um potencial biomarcador, são eles: Tempo de circulação pós irradiação, rapidez e sensibilidade, não variação da dose dependência in vitro $e$ in vivo, variação mínima entre diferentes indivíduos não irradiados e especificidade. 
Embora não haja hoje marcadores ideal que cumpram todos os pré-requisitos acima citados, estabeleceu-se o uso de técnicas citogenéticas como o padrão ouro para avaliar a dose-absorção estimada após exposição as radiações ionizantes (CASTROVOLIO 2013; MENDES et al., 2020).

\subsection{Dosimetria citogenética}

A dosimetria citogenica foi a técnica comumente utilizada em diversos acidentes envolvendo a exposição humana a radiações ionizantes, exposições de corpo inteiro ou frações de dois terços do corpo são bem detectadas pelas técnicas (AUGUSTA 1997).

As aberrações citogenéticas embora não especificas, são bastantes eficiente e replicáveis, baseiam-se em achados moleculares causados pelos danos afligidos ao material genético. Os achados mais comuns são as os dicêntricos, os anéis acêntricos, os fragmentos nucleares e os micronúcleos, o primeiro fortemente associado a exposição as radiações ionizantes sendo assim tem maior especificidade quanto a sua contagem quando comparado ao teste do micronúcleo que embora barato e de fácil aplicação pode ser causado por diversos outros agentes clastogênicos (AUGUSTA 1997; CASTRO-VOLIO 2013).

Para os fins de emprego da técnica usa-se comumente linfócitos periféricos (em metáfase) células de ampla circulação pelo corpo e em casos de exposição, de corpo inteiro ou em frações distintas do corpo, esperasse que haja uma alta probabilidade de o material coletado representar bem a realidade quanto a interação dos raios ionizantes com o meio de contato e aos danos de quebra do DNA (AUGUSTA 1997; CASTRO-VOLIO 2013).

Com essas aberrações citogenéticas é possível através de cálculos matemáticos uma correlação entre dose e a quantidade de achados no material citogenético estudado, possibilitando a construção de uma curva dose-resposta. $O$ uso para avaliação de pacientes expostos a radioterapia mostra-se em alguns estudos eficazes, inclusive para avaliações daqueles pacientes que apresentam uma alta radiossensibilidade, contudo necessitasse de mais embasamento teórico e empírico, sobretudo, para pacientes expostos a baixas doses (AUGUSTA 1997; CASTRO-VOLIO 2013; SOUZA-SILVA et al., 2014). 


\subsection{Outros potenciais biomarcadores}

\subsection{I $\mathrm{yH}_{2} \mathrm{AX}$}

A proteína $\mathrm{H}_{2} \mathrm{~A}$ é uma histona, que ao ser exposta a radiação ionizante será submetida a uma reação de fosforilação, resultado em um resíduo de serina a $\mathrm{yH}_{2} \mathrm{AX}$, portanto, alguns estudos a apresentam como provável bioindicadora da radiossensibilidade

Estudos anteriores demonstram a presença da $\mathrm{yH}_{2} \mathrm{AX}$ em locais de dupla quebra de DNA indicando que a quantidade de $\mathrm{yH}_{2} \mathrm{AX}$ está associada a esse marcador dosimétrico (ROGAKOU, 1999).

Chua et al. (2013) ao avaliarem os níveis de $\mathrm{yH}_{2} \mathrm{AX}$ em pacientes com câncer de mama, irradiados com 4 Gy em 5 e 24 horas, observou um aumento estatisticamente significativo de quebras das duplas fitas após 24 horas em relação ao controle com $p=0,004$. Contudo, Beaton et al. (2013) ao avaliarem pacientes tratados para câncer de próstata, sendo Io pacientes com prostite por radiação, ou seja, sabidamente radiossensíveis e 20 pacientes sem prostite cujas amostras foram posteriormente irradiadas com variadas doses $(0,2,4,6,8$ e ro Gy) e avaliadas após 24 horas em citômetro de fluxo não observaram resultados estatisticamente significativos entre os grupos controle e sensíveis.

Apesar de demonstrar uma elevação sérica dose-dependente, a y $\mathrm{y}_{2} \mathrm{AX}$ ainda não apresentou potencial para biomarcador da radiossensibilidade individual, soma-se o fato da $\mathrm{yH}_{2} \mathrm{AX}$ apresentar baixa sensibilidade após as 24 horas, sendo então uma técnica limitada após esse período de tempo.

\subsection{2 $\mathrm{P}_{53}$}

A p53 é uma das proteínas mais conhecidas e estudadas da atualidade foi descoberta em 1973, é uma proteína supressora tumoral, diretamente relacionada aos processos de proliferação e morte celular, dentre as principais funções estão à regulação do ciclo celular e o chekpoint mitótico nas fases Gi e G2 (NGUEYN, 2017).

Cavalcanti (2014) ao analisar amostras de linfócitos in vitro de 23 pacientes, expostos a variadas doses de radiação (o,5; I; 2 e 4 Gy), constataram um aumento na expressão da p53 por citometria de fluxo. Souza 2013, ao avaliar amostras de io pacientes com câncer de laringe, também observou um aumento significativo nos níveis de p53 após 
exposição a $2 \mathrm{~Gy}$, esses resultados corroboram com a possível indicação da p53 como biomarcador da radiossensibilidade individual.

Contudo os níveis basais desta proteína apresentam diferenças significativas entre os indivíduos o que pode dificultar o estabelecimento de um protocolo e replicação de ensaios clínicos. (ROSSNER ET AL, 2004).

\subsubsection{Citocinas}

Citocinas são pequenos ( 5 a $30 \mathrm{kDas})$ moduladores do processo imune e da resposta inflamatória, com tempo de meia vida curto são secretadas por diferentes estirpes celulares, atuam via receptores nas células alvos e ocasionam o aumento na expressão de genes específicos (RAMANI, 2015; VILCEK, 2004).

Apresentam efeitos radioprotetores e sensibilizadores já descritos na literatura como os observados no IFN- $\gamma$ que se mostrou capaz de elevar a letalidade celular em animais administrados com ela ou a IL-I2 que apresenta atividade radioprotetora na medula óssea. As IL-I, IL-6, IFN- $\gamma$, dentre outras, são responsáveis por modular a reação inflamatória pós-exposição. (Mukherjee, 2014; Di maggio et al, 2016).

Li et al. (2014) ao acompanharem mineradores de urânio (+ de 5 anos laborais) e avaliar os níveis de citocinas em soro, notou níveis elevados de citocinas pro inflamatórias, dentre elas o IFN-y o que correlacionado com outras citocinas pode ser um indicativo de estados inflamatório persistente.

Diversas citocinas apresentam níveis séricos elevados após exposição as radiações ionizantes, tornando-as candidatas como potenciais biomarcadores a exposição, contudo as citocinas tem manifestam forte pleiotropismo e apresentam diversas outras funções no metabolismo celular, denotando inespecificidade como biomarcadores da radiação (ABBAS, 2012).

\section{CONCLUSÃO}

Ambas as moléculas apresentam potencial para bioindicadores, contudo a y $\mathrm{y}_{2} \mathrm{AX}$ apresenta pouco tempo de meia-vida, enquanto a p53 mostram diferenças muitos variadas nos níveis basais interindividuais, já as citocinas apresentam forte pleiotropismo e diversas 
funções metabólicas distintas dificultado a especificidade como biomarcador para radiações ionizantes. Mais estudos são necessários para conhecer mais, elaborar protocolos e testar o uso dessas moléculas como biomarcadores.

\section{REFERÊNCIAS}

ABBAS, A. K.; LICHTMAN, A. H.; PILLAI, S. Imunol. Cel. e Mol., 7. Ed. [s.l: s.n.].

AZZAM, E. I.; JAY-GERIN, J. P.; PAIN, D. Ionizing radiation-induced metabolic oxidative stress and prolonged cell injury. Cancer Letters, v. 327, n. I-2, p. 48-6o, 2012.

Beaton L. A , Ferrarotto C. , Marro L. et al. Chromosome damage and cell proliferation rates in in vitro irradiated whole blood as markers of late radiation toxicity after radiation therapy to the prostate. Int. J. of Rad. Oncol,. V. 85, p. 1346-1352, 2013.

BECQUEREL, H. Sur les radiations invisibles émises par les corps phosphorescents. L'académie Des Sciences, p. 501-502. mar. 1896.

BERGONIE, J.; TRIBONDEAU, L. Interpretation of Some Results of Radiotherapy and an Attempt at Determining a Logical Technique of Treatment: De Quel ques Resultats de la Radiotherapie et Essai de Fixation d'une Technique Rationnelle. Radiation Research, p. 587-588. 25 mar. 1959

BURNET, N. G.; NYMAN, J.; TURESSON, I.; WURTN, R.; YAMOLD, J. R.; PEACOCK, J. $\mathrm{H}$. Prediction of normal-tissue tolerance to radiotherapy from in-vitro cellular radiation sensitivity. Lancet., v. 339, p. 1570-1571, 1992.

BURNET, N. G.; WURM, R.; NYMAN, J.; PEACOCK, J. H. Normal tissue radiosensitivity how important is it? Clin. Onco., v. 8, p. 25-34, 1996.

BARNETT, B., WEICHSELBAUM, R.R. Radiation as an immune modulator. Sem. in Radi. Onc., v. 23, p. 273-28o, 2013.

BRAYNER, C. M. Utilização da citometria de fluxo para avaliação dos níveis de expressão da proteína p53 em linfócitos do sangue periférico humano irradiados in vitro. 2005. Dissertação (Mestrado). Programa de Pós-Graduação em Tecnologias Energéticas e Nucleares, Universidade Federal de Pernambuco, Recife, 2005.

CASTRO-VOLIO, I. Indicadores citogenéticos para la identificación de exposición a radiación ionizante en humanos. Acta méd. costarric [online]. 2013, vol.55, n.3

CHUA, M. L. K.; ROTHKAMM K. Biomarkers of radiation exposure: Can they predict normal tissue radiosensitivity?. Clin. Onc., p. 610-616, 2013.

DA SILVA, M. A. DOSIMETRIA BIOLÓGICA EM PROTEÇÃO RADIOLÓGICA: ELABORAÇÃO DE CURVAS DOSE-RESPOSTA PARA"Co e'" Cs. PhD Thesis. UNIVERSIDADE DE SÃO PAULO, 1997. 
DI, MAGGIO; F. M.; et al. "Portrait of Inflammatory Response to Ionizing Radiation Treatment.” J. of Infla., v. I2, 18 fev.2or6.

FRANÇOIS, A. ET AL. Inflammation and Immunity in Radiation Damage to the Gut Mucosa. BioMed Res. inter., v. 2013, 18 fev. 2013.

HENDRY, J. H.; JEREMÍC, B.; ZUBIZARRETA, E.H. Normal tissue complications after radiation therapy.Rev.PanamSaludPublica, vol. 20, p.I5I-6o, 2006.

HOLST, L. R. Development Of Clinical Radiotherapy Since I896. Act. Onc., p. 995-1003, 1995.

INTERNATIONAL ATOMIC ENERGY AGENCY (IAEA). Planning National Radiotherapy Services: A Practical Tool. IAEA Hum. heal. ser.Vienna., n. I4, 2010.

LI, K. et al. Alteration of cytokine profiles in uranium miners exposed to long-term low dose ionizing radiation. The Sci. Wor. J., v. 2014, p. 216408, 2014.

MANDA, K.; GLASOW, A.; PAAPE, D.; HILDEBRANDET, G. Effects of ionizing radiation on the immune system with special emphasis on the interaction of dendritic and $\mathrm{T}$ cells. Fron. in Onc., 24 aug. 2012.

MENDES, M. E.; MENDONÇA, J. C. G.; HWANG, S.; GIORGIO, M. D.; LIMA F. F.; SANTOS, N. Calibration curves by 60 Co with low dose rate are different in terms of dose estimation - a comparative study. Genet Mol Biol. 2020 Feb 17;43(I)

MUKHERJEE, D.; COATES, P.J; LORIMORE, S. A.; WRIGHT, E. G. Responses to ionizing radiation mediated by inflammatory mechanisms. The J. of Patho. v. 232, n. 3, p. 289-99, 2014.

NGUYEN, D.; LIAO, W.; ZENG, S. X.; HUA, LU. Reviving the guardian of the genome: Small molecule activators of p53. Pharm. and Thera., 2017.

SILVA, E. C. DE S.; CAVALCANTI, M. B.; CARNEIRO, P. F. P. (2014). Radioterapia versus Radiossensibilidade Individual. Caderno De Graduação - Ciências Biológicas E Da Saúde - UNIT PERNAMBUCO, I(3), III-II7.

TURESSON L.; NYMAN J.; HOLMBERG E.; ODEN A. Prognostic factors for acute and late skin reactions in radiotherapy patients. Inter. J. Radi. Onc. Bio. Phy., v. 36, p.1065 - 1075, 1996.

TWARDELLA, D.; CHANG-CLAUDE, J. Studies on radiosensitivity from an epidemiological point of view-overview of methods and results. Radi. And onc., v. 62, n. 3, p. 249-260, 2002.

VILCEK, J.; FELDMANN, M. Historical review: Cytokines as therapeutics and targets of therapeutics. Cell Press: Tren. in Pharm. Sci., v. 25, n. 4, p. 201-209, abr. 2004.

WEST, C. M.; BARNETT, G. C Genetics and genomics of radiotherapy toxicity: towards prediction. Gen. Med., v. 3, 23 aug. 201r.

WRIGHT, E. G.; COATES, P. J. Untargeted effects of ionizing radiation: Implications for radiation pathology. MutationResearch: Genomeinstabilityanddisease, p. I19-132, II mai. 2006. 